\title{
Increase in Cadaver Organ Donation Rate at a Tertiary Care Hospital: 23 Years of Experience
}

\author{
Kapil G Zirpe ${ }^{1}$, Prasad Suryawanshi ${ }^{2}$, Sushma Gurav ${ }^{3}$, Abhijeet Deshmukh $^{4}$, Prajakta Pote ${ }^{5}$, Amit Tungenwar $^{6}$, \\ Ria Malhotra ${ }^{7}$
}

\begin{abstract}
Background: Transplantation of Human Organ Act was passed in India in 1994 to streamline organ donation and transplantation activities. It is time to retrospect ourselves and analyze the method to increase organ donation.

Type of study: Retrospective observational analysis.

Objectives: To evaluate the change in organ donation rate and reasons for changes in rates.

Subjects: Brainstem dead declared patients whose family consented for organ donations in the last 23 years (1997-2019) at Ruby Hall Clinic, Pune, India.

Materials and methods: Retrospectively demographic data of the brainstem dead declared donors, the primary diagnoses, comorbidities, and the complete data of their management till organ retrieval was assessed.

Results: One hundred cases in the age group 15-75 years (mean $41.6 \pm 15.3$ years) of brainstem death consented for organ donation were retrospectively studied. The period was divided into two groups, group I and group II included study duration from 1997 to 2013 and from 2013 to 2019 respectively. During the entire period, though the major cause of donor death remained road traffic accidents (RTA) in both the groups (84.21\% till 2013 vs $48.15 \%$ after 2013), the proportion of donors declared brain dead due to RTA dipped significantly after 2013 ( $p=0.004)$ and the non-RTA causes of brain dead contributed more than RTA causes ( $51.85 \%$ non-RTA vs $48.15 \%$ RTA). The major contributor among non-RTA causes was intracranial bleeds (5.26\% before 2013 vs $33.33 \%$ after $2013, p=0.014)$. Compared to the previous 17 years (from 1997) there were more than fourfold rise in the rate of transplantation in the last 6 years (2014-2019) at our institute. Kidneys were retrieved from $90 \%$ donors followed by cornea $84 \%$, liver $65 \%$, heart $22 \%$, skin $7 \%$, lungs $6 \%$, and pancreas $5 \%$.

Conclusion: We have observed that the cadaveric organ donation rate significantly improved after 2013. Reasons might be widening of the donor pool by the selection of more of non-RTA brain death donors over RTA, acceptability of elderly population donor ( $>60$ years) by our transplant teams, early identification of potential organ donor, and better protocol-based management of the cadaver organ donor.

Keywords: Brainstem death, Endotracheal intubation, Hemorrhage, Mechanical ventilation, Steroids, Stroke.

Indian Journal of Critical Care Medicine (2020): 10.5005/jp-journals-10071-23578
\end{abstract}

\section{INTRODUCTION}

Organ donation has been hailed as a divine concept by many who consider the human body as a gift, which can be passed on to the needy and dying fellow beings when it has served its purpose for oneself. An altruistic behavior was identified as a motivator for consenting for organ donation. ${ }^{1}$ The kind act of willingly consenting to give his/her vital organs for donation after death empowers them to live again through the recipient's life. "One Donor Can Save Eight Lives". Thus, if multiple organs are procured, then the single donor lives life through multiple recipients' life.

Data from the WHO Global Observatory on Donation and Transplantation (GODT) showed that over 130,000 solid organ transplants are performed worldwide, but this suffices only less than $10 \%$ of the global need. ${ }^{2}$

The organ donation rate in India has increased from a dismal 0.05 per million populations to 0.8 per million populations in a span of few years. ${ }^{3,4}$ Organ donation rates in India are minuscule compared to Croatia's 36.5, Spain's 35.3, and USA's 26 per million, respectively. Some of the factors attributed for low organ donation imbalance between demand and supply of factors like the spiritual belief of life after birth, ${ }^{5}$ low awareness leading to the negative attitude towards donation, ${ }^{6}$ and loopholes in "The Transplantation of Human Organs Act" (THOA) act prior to the amendments in $2014 .{ }^{7}$
${ }^{1-7}$ Neuro Trauma Unit, Grant Medical Foundation, Pune, Maharashtra, India

Corresponding Author: Kapil G Zirpe, Neuro Trauma Unit, Grant Medical Foundation, Pune, Maharashtra, India, Phone: +91 9822844212, e-mail: kapilzirpe@gmail.com

How to cite this article: Zirpe KG, Suryawanshi P, Gurav S, Deshmukh A, Pote $P$, Tungenwar A, et al. Increase in Cadaver Organ Donation Rate at a Tertiary Care Hospital: 23 Years of Experience. Indian J Crit Care Med 2020;24(9):804-808.

Source of support: Nil

Conflict of interest: None

The number of men, women, and children on the national transplant waiting list as of March 2020 is about more than 112,000, and every 10 minutes one person is added to the transplant waiting list. Twenty people die each day waiting for an organ transplant. In 2019, there were 19,267 donors, 39,718 transplants, and 112,568 waiting list. (Data from optn.transplant.hrsa.gov and OPTN/SRTR annual report).

India ranks 1st in the number of road accident deaths across the 199 countries reported in the World Road Statistics. As per the WHO Global Report on Road Safety 2018, with more than 1.5

(c) The Author(s). 2020 Open Access This article is distributed under the terms of the Creative Commons Attribution 4.0 International License (https://creativecommons. org/licenses/by-nc/4.0/), which permits unrestricted use, distribution, and non-commercial reproduction in any medium, provided you give appropriate credit to the original author(s) and the source, provide a link to the Creative Commons license, and indicate if changes were made. The Creative Commons Public Domain Dedication waiver (http://creativecommons.org/publicdomain/zero/1.0/) applies to the data made available in this article, unless otherwise stated. 
lakh deaths, India accounts for almost $11 \%$ of the accident-related deaths in the world. ${ }^{8}$

Accident-related deaths in India in 2018 were 151,417 and in nearly $40-50 \%$ of road accident fatalities, the cause of death was a head injury. ${ }^{9}$ We can say if $5-10 \%$ of all brain-dead patients are considered properly for organ harvesting, there would be no requirement for a living person to donate organs. ${ }^{10}$

Although the road accidents contribute to the highest proportion of cadaveric donors, it is important to revisit our criteria for organ selection from the cadaveric donor. We have noticed that when the efforts were put in to widen the spectrum of diseased organ donors, the rate of organ donation was also peaked. ${ }^{11}$

A potential brain-dead organ donor (PBDD) is defined by the presence of either brainstem death or a catastrophic and irreversible brain injury that leads to fulfilling the brainstem death criteria. ${ }^{12,13}$

Intensivist plays an important role in giving care to potential organ donor since all the potential donor enter ICU at some point in time. ${ }^{12,14}$

\section{A IM}

This institute level retrospective study was planned to analyze the trends of increased organ donations in the last 23 years (from 1997 till 2019) and to know the positive initiatives taken toward enhancement of donation rate.

\section{Materials and Methods}

Data were retrieved from medical records of the brain-dead organ donors in the last 23 years (1997-2019) at Ruby Hall Clinic, Pune, and were evaluated. The study period was divided into two eras, the first 1997-2013 and the second era 2014-2019.

Information regarding donor characteristics like age, gender, primary cause of brain death, comorbid conditions, time of declaration of brain death, etc., were recorded. All the available information on the respiratory, cardiac, hematology, biochemistry, urine parameters along with the details of donor management such as invasive line, hormonal therapy, cardiovascular support, fluid therapy, and details of antibiotics use were recorded. The time of the first and second apnea tests was noted and the details of organs retrieved for transplant were also documented.

Primary data were collected in paper-based pro forma and the data were then entered in Microsoft Excel spreadsheets. Statistical analysis was done on IBM SPSS Statistics version 20. Means were compared using independent-sample $t$ test. A $p$ value of less than 0.05 was taken as significant.

\section{Results}

A total of 100 cases in the age group 15-75 years (mean $41.6 \pm 15.3$ years) of brainstem death record were studied. Relatives of these 100 brainstem dead patients had consented for organ donation. The cohort consisted of 84 males and 16 females. (M:F ratio 1:0.19). Interestingly the average age of the donors in the first era (19972013) was $34.89 \pm 11.67$ years which increased significantly in the second era to $43.24 \pm 15.46$ years $(p=0.029)$. Also, the maximum age of the donor which was only 50 years in the first era went up to 75 years in the second era. The minimum age also went down from 18 years to 15 years during the second era.

The second era of 6 years witnessed the significant widening of the spectrum of donors after 2013. While the major cause of donor's brainstem death remained (RTA) in both the groups (84.21\% till 2013 vs $48.15 \%$ after 2013 ), the proportion of donors declared brain dead due to RTA dipped significantly in the second era (after 2013) ( $p=$ 0.004). The percentage of other causes than RTA that contributed to brainstem death was more than half in the second era. $151.85 \%$ non-RTA vs $48.15 \%$ RTA). The major contributor among non-RTA causes in recent years was intracranial bleeds $(5.26 \%$ in the first era vs $33.33 \%$ in the second era, $p=0.014$ ) (Table 1 ).

Although our organ donation program started in 1997, the frequency of brainstem dead declared organ donors was very low till 2013. Till 2013 in 8 different years, there were no organ donation cases and hence no transplant was carried out. In the year 2014, few proactive measures were adopted which aimed at enhancing the numbers of brainstem dead organ donors which came to fruition in the subsequent years. The peak number was achieved in 2016, 28 cases of brainstem death organ donors were recorded. Compared to 19 cases of brainstem dead organ donations till 2013, a visible fourfold rise was observed in the second era. Ninety cases were recorded in the second era 2013-2019 (Fig. 1).

Kidneys were retrieved from $90 \%$ donors followed by cornea $84 \%$, liver $65 \%$, heart $22 \%$, skin $7 \%$, lungs $6 \%$, and pancreas $5 \%$ (Fig. 2).

\section{Discussion}

Although the Transplantation of Human Organs and Tissues Act has come into existence in the year 1994, the journey of organ donation and transplantation (ODT) continues to be still in the infancy stage. ${ }^{2,15}$ Our institute started its first transplant in 1997, its journey to date was not an easy ride. In the consultative meet at Madrid 2010, India was categorized in the intermediate stage (level 3) for ODT capacity. ${ }^{16}$ Compared to the previous 17 years, our

Table 1: Shows dermographic characteristics such as age, sex and primary cause of brainstem death

\begin{tabular}{lllll}
\hline & & Cases between $(1997-$ & Cases between $(2014-$ \\
Donor characteristics & Total cases $(n=100)$ & 2013) $(n=19)$ & $2019)(n=90)$ & $p$ \\
\hline Average age (mean \pm SD) & $41.64 \pm 15.26$ & $34.89 \pm 11.67$ & $43.24 \pm 15.46$ & $0.029^{*}$ \\
Males & 84 & $17(89.47)$ & $67(82.72)$ & 0.472 \\
Upper age of donor & 75 & 50 & 75 & na \\
Minimum age of donor & 16 & 19 & 16 & na \\
RTA with head injury & 55 & $16(84.21)$ & $39(48.15)$ & $0.004^{* *}$ \\
HTN bleed-28 & 28 & $1(5.26)$ & $27(33.33)$ & $0.014^{*}$ \\
Ischemic infarction-10 & 10 & $1(5.26)$ & $9(11.11)$ & 0.44 \\
Tumor-3 & 3 & 0 & $3(3.70)$ & 0.397 \\
Fall-3 & 3 & 0 & $3(3.70)$ & 0.397 \\
Assault-1 & 1 & $1(5.26)$ & 0 & na \\
\hline
\end{tabular}

*less significant; ${ }^{* *}$ high significant 


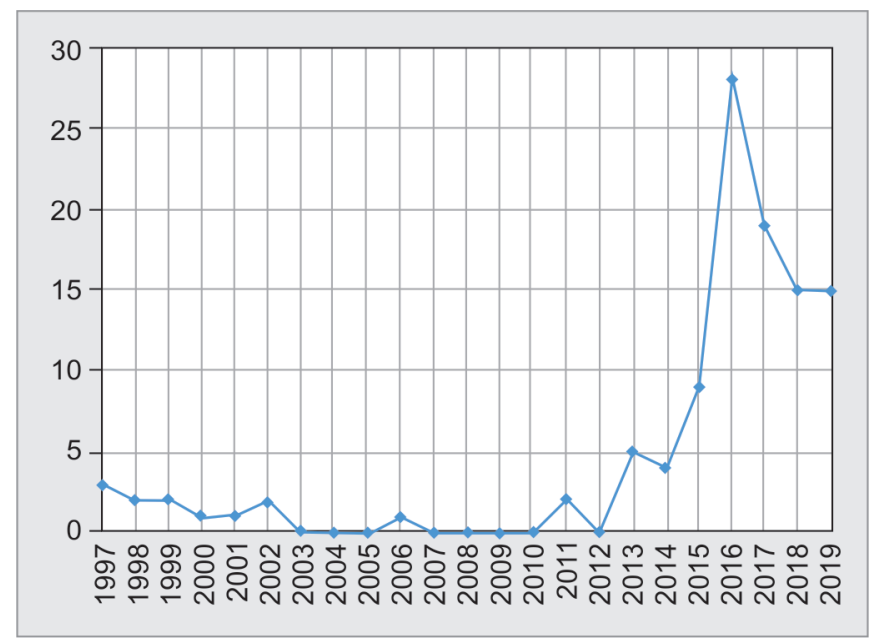

Fig. 1: Year-on-year distribution of cadaveric transplants (from 1997 till 2019)

institute recorded more than fourfold rise in number of transplants after 2013 which is fairly in line with the trend of overall transplants in India, where it is reported that the deceased donation rate went up over four times in 6 years from 2012 to $2017 . .^{15}$ An increase of $2.98 \%$ of transplanted solid organs transplants was reported in 2013 by the global observatory on organ donation ${ }^{2}$

Looking at the Indian scenario, certain provisions were included to ensure that the onus of responsibility for commercial organ donation was shifted to the organ donors, recipients, treating doctors, and hospital administrators. The punishment for forged documents and false affidavits was considerably enhanced and could go up to 1 crore rupees or 10 years in jail. Provisions to help push forward the deceased donation program were also included. ${ }^{7,8}$

It is seen that only a few states have been able to perform deceased donation transplantation. Maharashtra is one of the leading states who do it regularly and have a proper system for organ donation transplantation ${ }^{17}$ and contribute to the bulk of India's total donation rate of 0.8 PMP. $^{18}$

The multipronged strategy to enhance the cadaveric donor transplants focused majorly on widening the spectrum of donors. The average age of the donors till 2013 , which was $34.89 \pm 11.67$ years, increased significantly after 2013 to $43.24 \pm 15.46$ years ( $p=$ 0.029). The shifting of the maximum age of the donor from 50 years till 2013 to 75 years after 2013 demonstrates the institutional efforts to better manage brain-dead donors of the geriatric cases as well.

Shifting the focus towards non-RTA cases also added significantly to the number of potential donors. While the conventional pool of cases coming from RTA was maintained well, additional efforts were put in for non-RTA cases. As a result, the recent 6 years witnessed more brain-dead cases due to other causes than RTA compared to RTA.(51.85\% non-RTA vs $48.15 \%$ RTA).

For the successful organ transplantation, precise medical management of a potential organ donor is the most crucial issue, and it asks for a multidisciplinary team approach. ${ }^{18,19}$ Our standardized protocol for donor management reinforced by the in-house transplant team helped us in sustaining hemodynamic variables and laboratory parameters within the normal ranges for the donors, which is assumed to be the preferred goal for successful organ donation. . $^{190}$

Discussing organ donation with the relatives of the brain dead is never easy. ${ }^{21}$ It is important to instill confidence and build trust

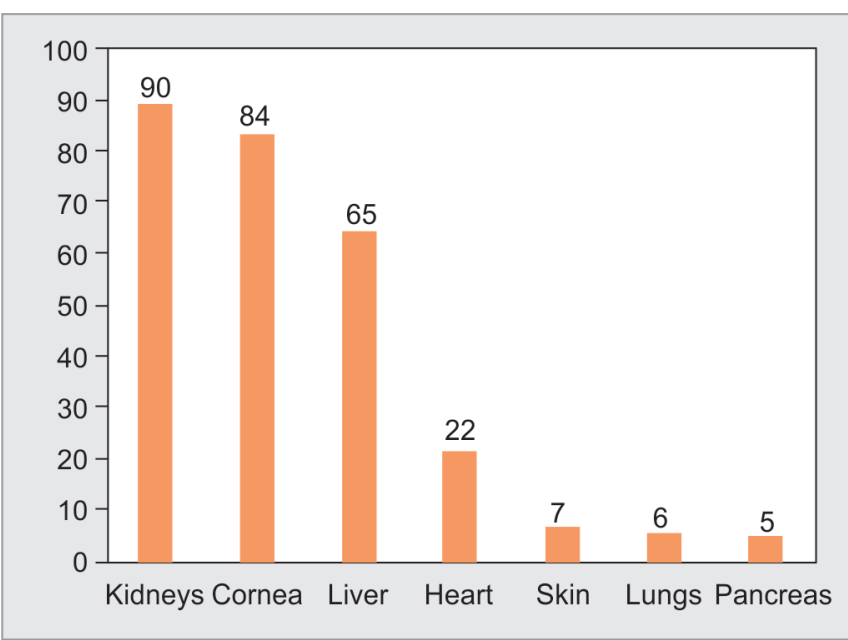

Fig. 2: Frequency distribution of organs retrieved from brain-dead donors

while communicating with the relatives of the deceased donor. An Indian study by Balwani et al. revealed that about $59 \%$ of the study participants believed that there was a potential danger of donated organs being misused, abused, or misappropriated. ${ }^{22}$ The same study also found that $74.41 \%$ of participants were unaware of any legislation regarding organ donation.

The recent surge in the donation can also be attributed to the enhanced communication strategy that was adopted by our team. It was ensured that the communication with the relatives was done at the appropriate time and the tone being utmost empathetic. A transparent and unbiased system of organ allocation is followed and is explained to the donor families to boost the trust and confidence in the system. A study was done in California by Saub et al. ${ }^{23}$ revealed that speaking to a physician about organ donation positively influenced the likelihood to donate an organ.

As and when required involvement of senior consultants from the institute is done to positively influence the donor families.

Our institutional experience of 23 years suggests that adherence to standardized donor management protocols, focus on non-RTA and non-trauma brainstem dead cases and devising effective communication strategy can result in a multifold rise in brainstem dead organ donations. However, considerable efforts need to be taken on the policy level to support organ donation from patients that are cardiac dead which will provide the opportunity to increase the donor pool and most importantly assure that every opportunity is taken to carry out the wishes of the donor family. Delinking brainstem death condition from organ donation remains a big challenge associated in the current legal scenario.

Brainstem death as death is only mentioned in the transplant law and has been linked to organ donation. It is not mentioned in the Registration of Births and Deaths Act of $1969 .{ }^{24}$ Therefore, the cases with brainstem death and non-beating heart can't get disconnected from the ventilator creating a legal and ethically challenging situation. The transplant law ought to collectively be at an advantage for all the citizens of our country, and pave a way forward for enhancing the transplant numbers.

\section{Limitations of our Study}

Our retrospective study has several limitations. First, it's retrospective analysis of cases of organ donation from a single tertiary care center. Secondly, the retrospective nature of the study could have excluded the data due to incomplete medical records 
conversion rate of total brainstem death to organ donation could not be interpreted. We were not able to study issues related to consent among included cases. So it was not possible to comment on the correlation of willingness of relatives for consent among RTA vs. non-RTA donors. As we have observed a significant difference between the age of two categories, younger age might have been prevented relatives of the victim from consenting earlier.

We could put forth few measures implemented by us in our institute for improving the care of potential organ donation. These steps when put together might have led to an increase in organ donation.

\section{Recommendations to Improve Organ Donation based on our Institute Experiences}

Based on our study and extensive search, we can make the following recommendations.

- Extended criteria for organ donation: accepting the elderly population as donors and including more non-RTA donors may improve the organ donation rate. ${ }^{25,26}$

- Early recognition of potential organ donors: with regard to the identification of potential donors; we recommend that institutes should develop a protocol that ensures all potential donors are identified in the early stage. Such a systemic approach may help to salvage donors. ${ }^{12,27}$

- Protocol driven approach for a PBDD: multi-faceted team (intensivist, social worker, trained nurse, radiologist, and a comfortable waiting area for the relative of organ donor, procurement team) checklist development. ${ }^{12,27}$

- Training of healthcare workers could be a promising intervention to increase the donor pool. ${ }^{12}$

- Effective and clear communication with family may be crucial in improving consent for organ donations. ${ }^{28,29}$

Table 2: $A B C$ approach for organ donation

\begin{tabular}{ll}
\hline A & Etiology of brainstem death or irreversible coma \\
B & Brain death alert signs \\
C & Contraindication to organ donations \\
\hline
\end{tabular}

Flowchart 1: Protocol-driven organ donation approach in our institute

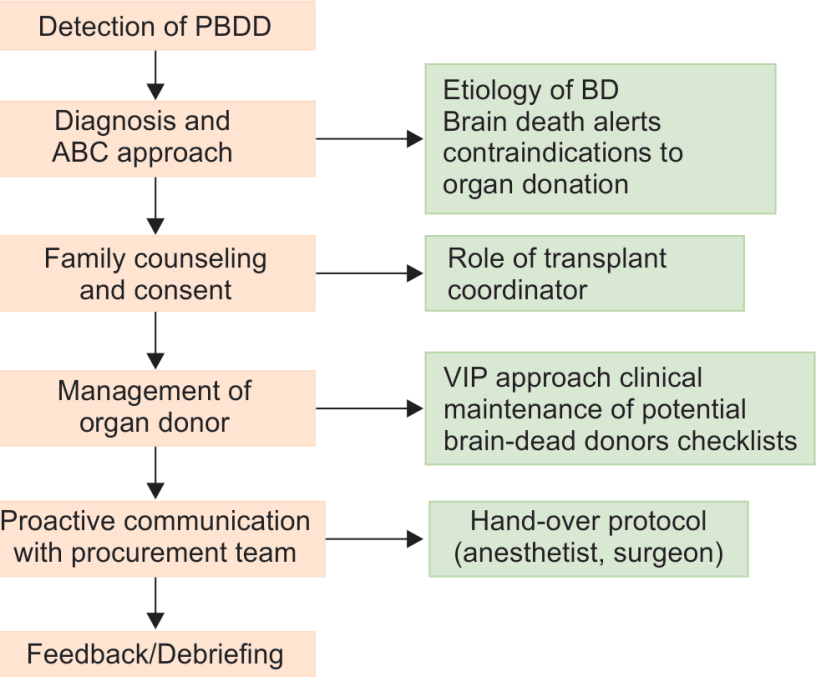

- Appointment of a transplant coordinator: they help in counseling of families for taking consent for organ donation and coordinate the process of donation and transplantation. ${ }^{28,29}$

A protocol-driven and multisystem $A B C$ approach for organ donation, suggested by our team: (Table 2 and Flowchart 1).

\section{Conclusion}

Our aim should not be only to increase the number of donated organs but also to increase their quality and to reduce cardiac arrests in PBDD. This will also preserve long-term graft function. ${ }^{28}$ Implementation of a multidisciplinary approach will help us to identify potential organ donors, proper maintenance of organ donors, proper counseling of relatives and maintain proper communication between the procurement team and intensivist. Finally, there should also be a proper body handover protocol. Let's move our organ donation goal from the institute level to the national level and follow the organ procurement laws, and pave a way forward for enhancing the transplant numbers.

\section{References}

1. Newton JD. How does the general public view posthumous organ donation? A meta-synthesis of the qualitative literature. BMC Public Health 2011;11:791. DOI: 10.1186/1471-2458-11-791.

2. Anika Sulania A, Sachdeva S, Jha D, Kaur G, Sachdeva R. Organ donation and transplantation: an updated overview. J Med Sci 2016;2:18-27.

3. Pandit RA. Brain death and organ donation in India. Indian J Anaesth 2017;61(12):949-951. DOI: 10.4103/ija.IJA_729_17.

4. Abraham G, Vijayan M, Gopalakrishnan N, ShroffS, Amalorpavanathan $J$, Yuvaraj A, et al. State of deceased donor transplantation in india: a model for developing countries around the world. World J Transplant 2016;6(2):331-335. DOI: 10.5500/wjt.v6.i2.331.

5. Lock M, Honde C. Reaching consensus about death: heart transplants and cultural identity in Japan. Social Science Perspectives on Medical Ethics. Philadelphia: University of Pennsylvania; 1990. p. 99-119.

6. Veerappan I. Deceased donor kidney transplantation in India. Health Sci 2012;1(2):JS010.

7. Nagral S, Amalorpavanathan J. Deceased organ donation in India: where do we go from here? Indian J Med Ethics 2014;11(3):162-166.

8. WHO Global Report on Road Safety 2018 Available from:https://www. who.int/violence_injury_prevention/road_safety_status/2018/en/. [Last accessed on 2020 Feb 19].

9. Kirankumar R, Satri V, Satyanarayana V, Ramesh Chandra VV, Madhusudan M, Sowjanya J. Demographic profile, clinical features, imaging and outcomes in patients with traumatic brain injury presenting to emergency. J Clin Sci Res 2019;8(3):132-136.

10. Nallusamy S, Shyamalapriya, Balaji, Ranjan, Yogendran. Organ donation - current indian scenario; Organ donation - current Indian scenario. J Pract Cardiovasc Sci 2018;4(3):177-179. DOI: 10.4103/jpcs. jpcs_59_18.

11. Saidi RF, Hejazii Kenari SK. Challenges of organ shortage for transplantation: solutions and opportunities. Int J Organ Transplant Med 2014;5(3):87-96.

12. Zirpe $\mathrm{K}$, Gurav $\mathrm{S}$. Brain death and management of potential organ donor: an indian perspective. Indian J Crit Care Med 2019;23(Suppl 2):S151-S156. DOI: 10.5005/jp-journals-10071-23194.

13. Tanim Anwar ASM, Jae-Myeong L. Medical management of braindead organ donors. Acute Crit Care 2019;34(1):14-29. DOI: 10.4266/ acc.2019.00430.

14. Meyfroidt G, Gunst J, Martin-Loeches I. Management of the braindead donor in the ICU: general and specific therapy to improve transplantable organ quality. Intensive Care Med 2019;45(3):343-353. DOI: 10.1007/s00134-019-05551-y. 
15. Shroff S. Twenty-five years of transplantation law in India-Progress and the way forward. Indian J Transplant 2019;13(3):151. DOI: 10.4103/ ijot.ijot_32_19.

16. Jacquelinet $C$, Jha V, Levin A. Report of the Madrid consultation: part 2: reports from the health system. Falls in working groups. Transplantation 2011;91(Suppl 11):S67-S114.

17. Available from: https://www.mohanfoundation.org/deceasedorgandonation-in-india.asp. [Last accessed on 2020 Mar 20].

18. Shroff S, Navin S. National data-deceased organ donation and transplantation. Indian Transplant Newsletter 2017;16(50):49. Available from: https://www.itnnews. co.in/indian-transplantnewsletter/issue50/National- Data-Deceased Organ-Donation-andTransplantation-587.htm [Last accessed on 2020 Mar 20].

19. McKeown DW, Bonser RS, Kellum JA. Management of the heartbeating brain-dead organ donor. Br J Anaesth 2012;108(Suppl 1):i96-i107. DOI: 10.1093/bja/aer351.

20. Powner DJ, Darby JM, Kellum JA. Proposed treatment guidelines for donor care. Prog Transplant 2004;14(1):16-26. DOI: 10.1177/152692480401400103.

21. Evans D. Brain death. The family in crisis. Intensive Crit Care Nurs 1995;11(6):318-321. DOI: 10.1016/S0964-3397(95)80344-0.

22. Balwani MR, Gumber MR, Shah PR, Kute VB, Patel HV, Engineer DP, et al. Attitude and awareness towards organ donation in western India. Ren Fail 2015;37(4):582-588. DOI: 10.3109/0886022X.2015.1007820.

23. Saub EJ, Shapiro J, Radecki S. Do patients want to talk to their physicians about organ donation? attitudes and knowledge about organ donation: a study of orange county, California residents. J Commun Health 1998;23(6):407-417. DOI: 10.1023/ A:1018754023705.

24. The Registration of Births and Deaths Act 1969. Available from: http:// cms.tn.gov.in/sites/default/files/acts/birth_death_act_e_1.pdf [Last accessed on 2020 Marl 15].

25. Dronacharya Routh SS, Naidu CS, Rao PP, Sharma AK, Ranjan P. Comparison of outcomes in ideal donor and extended criteria donor in deceased donor liver transplant: a prospective study. Int J Surg 2014;12(8):774-777. DOI: 10.1016/j.ijsu.2014.06.003.

26. Nair A, Hashimoto K. Extended criteria donors in liver transplantationfrom marginality to mainstream. Hepato Biliary Surg Nutr 2018;7(5):386-388. DOI: 10.21037/hbsn.2018.06.08.

27. Witjes M, Kotsopoulos AMM, Otterspoor L, Herold IHF, Simons $\mathrm{KS}$, Woittiez K, et al. The implementation of a multidisciplinary approach for potential organ donors in the emergency department. Transplantation 2019;103(11):2359-2365. DOI: 10.1097/ TP.0000000000002701.

28. Srivastava A, Mani A. Deceased organ donation and transplantation in India: promises and challenges. Neurology India 2018;66(2):316-322. DOI: 10.4103/0028-3886.227259.

29. Martin-Loeches I, Sandiumenge A, Charpentier J. Management of donation after brain death (DBD) in the ICU: the potential donor is identified, what's next? Intensive Care Med 2019;45(3):322-333. DOI: 10.1007/s00134-019-05574-5. 